desirable. The phrase 'nuclear species' is scarcely an improvement on the now common 'nuclide'.

Many readers of this book may wish that the author had adopted a rather broader treatment, by incorporating a wider range of relevant experimental material (for example, the systematics of the masses of stable nuclei and their actual observed abundances are relevant topics) ; and also giving more indication of how the facts elicited are related to current theories of nuclear structure. However, this would probably have resulted in a much larger work, and Prof. Feather hints at the restraint he has had to exercise in order to keep within the limits he has set himself. In dealing with the "magic numbers", he remarks (p. 26), "the temptation is great to embark at once on an ambitious attempt to find their interpretation in a 'shell model' . . . that temptation we shall for the present resist". But by the time all the experimental material is presented, there seems to be no space in this book for this fuller interpretation, and the reader must content himself with the valuable presentation of the material itself. S. Devons

\section{LOCOMOTION OF ANIMALS}

How Animals Move

By Prof. James Gray. (The Royal Institution Christmas Lectures, 1951.) Pp. xii $+114+15$ plates. (Cambridge: At the University Press, 1953.) $16 s$. net.

A BOUT twenty-five years ago Prof. James Gray A turned from his classic researches on cytology to start his investigations on a very different subject, the mechanics and physiology of the locomotion of animals. Since then the vigorous Cambridge school of research into this aspect of zoology has grown up around his pioneer work, and a large volume of literature records the results of its experiments and observations on all groups of the animal kingdom from Protozoa to Mammalia. Prof. Gray has not yet given the scientific world a book digesting and integrating the great mass of new knowledge that he and his colleagues have discovered; but in the meantime he has done something even more difficult-he has written a book for children that sets forth the basic principles of the subject clearly and simply to make a most fascinating story.

The book introduces animal locomotion with a consideration of certain simple laws of mechanics and, using the motor-car and the lever as familiar examples to lead up to the more complicated mechanisms of animals, shows that all locomotion is governed by the same mechanical principles. Muscular contraction is described; and the action of the motor and sensory nerves, and the proprioceptor sense organs, including the semi-circular canals, is demonstrated by analogy with the controls and dashboard instruments of a machine. After these foundations are laid, the remaining five chapters discuss animals themselves and develop the story of locomotion from swimming, through walking and running, jumping and creeping, to gliding and flapping flight.

Prof. Gray avoids writing-down, and by the aid of clear diagrams and interesting examples he makes his technical details easily understood and shows how the structure of an animal is correlated with its way of life, though he does not, of course, venture to speculate whether structure determines function or vice versa. His well-chosen illustrations of the various points that he makes hold the attention and are full of surprises for the newcomer to the subject. The chapter on swimming demonstrates how unreliable the eye is when observing movement, and shows the necessity for using recording instruments when accurate analysis of phenomena is desired. The speed of a fish darting through the water is much less than it appears to be; a trout dashing away with the fly and making the reel scream round is taking the line out at only 3 m.p.h., and a heavy salmon putting a pull of $1 \mathrm{lb}$. on the line necessitates a force of 12$13 \mathrm{lb}$. on the hands at the butt to hold the rod stationary. But the acceleration of a fish is great; starting from rest the maximum speed is attained in $1 / 20$ sec., an acceleration of $140 \mathrm{ft}$. per sec. per sec. A 600-lb. sword-fish travelling at 10 m.p.h. and colliding head-on with a wooden ship moving at the same speed strikes it with a force at the tip of the sword of more than $4 \frac{1}{2}$ tons-the surprising thing is, not that the sword penetrates the wood, but that it does so without itself being smashed in the process.

Thus the theme is continued: the electrical field surrounding Gymnarchus that allows it to find its way through muddy water; the evolution of legs from fins; the paces of terrestrial animals; how a kangaroo could jump over St. Paul's Cathedral if its leap were proportional to that of a flea, and why it cannot; the mechanics of the snake's movements; the flight of pigeons, albatrosses and bats; ultrasonic echo-location; and the function of halteres.

The author says in concluding his book: "The more we learn about living animals, the more beautiful their activities appear; and in a human world so much concerned with ugly engines of destruction, the concept of natural beauty provides welcome relief". Here speaks the true naturalist in the best sense, and he has been so successful in expounding his subject that few who take up his book will be able to put it down until they have devoured it all. This is popular science as it should be, and one hopes that Prof. Gray's little masterpiece will have the wide success that it deserves.

L. Harrison Matthews

\section{PSYCHOLOGY OF PERSONALITY}

The Logic of Personality

By Bernard Mayo. Pp. 188. (London : Jonathan Cape, Ltd., 1952.) 10s. 6d. net.

THE main virtue of Mr. Mayo's book lies in its trenchant logical analysis of the question: What is personality ? He shows that certain meaningless questions about personality can be replaced by meaningful ones. At first sight this may not seem a very impressive contribution. We begin to see its importance, however, when we follow the author in tracing the consequences of his views for discussions of personality in relation to art, ethics, and certain linguistic usages, and to the cognitive bias in philosophical theories of perception. The book could be studied with profit by personality testers, factor analysts, thematic apperceptionists, and students of Rorschachiana and the new journal Szondiana.

Mr. Mayo's discussion is marred on occasion by curious ideas about the psychology of personality. $\mathrm{He}$ supposes that the psychologist is only concerned with indirect knowledge, for example, such as may be embodied in or derived from testimonials, not with direct interpersonal knowledge. He thus appears 